\title{
Enhanced Aerobic Degradation of 4-Chlorophenol with Iron-Nickel Nanoparticles
}

Wenjuan Shen, Yi Mu, Bingning Wang, Zhihui Ai, * and Lizhi Zhang

Key Laboratory of Pesticide \& Chemical Biology of Ministry of Education, Institute of Environmental Chemistry, College of Chemistry, Central China Normal University, Wuhan 430079, People's Republic of China

*Corresponding author. Phone/fax: +86-27-6786 7953.

Email address: jennifer.ai@ mail.ccnu.edu.cn

\begin{abstract}
In this study, we demonstrate that the bimetallic iron-nickel nanoparticles (nZVIN) possessed an enhanced performance in comparison with nanoscale zero-valent iron (nZVI) on aerobic degradation of 4-chlorophenol (4-CP). The 4-CP degradation rate constant in the aerobic nZVIN process (nZVIN/Air) was 5 times that in the classic nZVI counterpart system (nZVI/Air). Both reactive oxygen species measurement and inhibition experimental results suggested that hydroxyl radicals were the major active species contributed to aerobic 4-CP degradation with nZVI, on contrast, superoxide radicals predominated the 4-CP degradation in the nZVIN/Air process. High performance liquid chromatography and gas chromatography-mass spectrometer analysis indicated the intermediates of the nZVI/Air system were p-benzoquinone and hydroquinone, which were resulted from the bond cleavage between the chlorine and
\end{abstract}


carbon atom in the benzene ring by hydroxyl radicals. However, the primary intermediates of 4-CP found in the nZVIN/Air system were phenol via the direct dechlorination by superoxide radicals, accompanying with the formation of chloride ions. On the base of experimental results, a superoxide radicals mediated enhancing mechanism was proposed for the aerobic degradation of 4-CP in the nZVIN/Air system. This study provides new insight into the role of bimetallic nickel on enhancing removal of organic pollutants with nZVI.

Keywords: Iron-nickel bimetallic nanoparticles; Molecular oxygen activation; 4-Chlorophenol; Reactive oxygen species

\section{Introduction}

Recently, the applications of nanoscale zero-valent iron (nZVI) for the oxidative remediation of environmental contaminants in the presence of molecular oxygen have been received considerable attention [1-5]. Due to the electron donor nature of iron, nZVI can active molecular oxygen (nZVI/Air system) to generate reactive oxygen species (ROS) including of hydrogen peroxide $\left(\mathrm{H}_{2} \mathrm{O}_{2}\right)$, superoxide radical $\left(\cdot \mathrm{O}_{2}{ }^{-}\right)$, and hydroxyl radical $(\bullet \mathrm{OH})$, which are capable of oxidizing or even mineralizing organic contaminants that cannot be removed by nZVI reductively [6]. However, the low ROS generation efficiency retards the application of nZVI/Air process for remediation of organic pollution. This drawback could be overcome by introducing another metal such as $\mathrm{Pd}, \mathrm{Pt}, \mathrm{Ni}, \mathrm{Ag}$, and $\mathrm{Cu}$ into nZVI to form so-called bimetallic nanoparticles to 
enhance the yields of oxidants in nZVI/Air process [7-15]. For instance, Xie found that Ni-Fe bimetal prepared by ball milling method possessed high 4-chlorophenol (4-CP) dechlorination activity [16]. Sedlak's group reported that Ni coated Fe nanoparticles showed a higher efficiency for oxidant production relative to $\mathrm{Ni}-\mathrm{Fe}$ alloy nanoparticles based on Ni content [17].

Generally, aerobic nZVI/Air process for oxidation of organic pollutants is highly dependent on the yields and species of ROS generated, higher yields of oxidants could accelerate oxidative degradation, moreover, species of ROS might influence the degradation pathway of organic molecules due to the difference in redox activity of $\mathrm{H}_{2} \mathrm{O}_{2}, \cdot \mathrm{O}_{2}{ }^{-}$, and $\bullet \mathrm{OH}$ oxidants. Among them, $\bullet \mathrm{OH}$ which is the most oxidative species can oxidize organic contaminants non-selectively, while $\cdot \mathrm{O}_{2}{ }^{-}$could simultaneously oxidize and reduce organic pollutants [10]. Although nZVI based bimetallic nanoparticles with enhanced yields of oxidants have been examined, the nature of the ROS generation and the role of individual ROS species on the degradation pathway is not well understood.

4-chlorophenol (4-CP), which was widely used as precursor for the synthesis of pesticides, herbicides, disinfectants, and wood preservatives, has been listed as one of the top priority pollutants by USEPA because it is irritant to the respiratory and central nervous systems at low levels, and can induce cancer at higher doses [18]. 4-CP was often found in high quantity in the wastewater from various industrial sectors, thus effective removal of 4-CP in contaminated environment is of great significance.

Previously, we demonstrated that $77.8 \%$ of $4-\mathrm{CP}$ was degraded in 7 hours in the 
nZVI/Air process and proposed a two-pathway molecular oxygen activation mechanism by nZVI [19]. In this study, we prepared bimetallic iron-nickel nanoparticles (nZVIN) and compared the aerobic 4-CP degradation as well as the yields and species of ROS generated over the nZVIN/Air and nZVI/Air systems. The purpose of this study is to clarify the role of bimetallic nickel on the molecular oxygen activation mechanism with nZVI and to develop more efficient aerobic oxidation strategy for environmental remediation.

\section{Materials and methods}

\subsection{Chemicals}

Sodium borohydride $\left(\mathrm{NaBH}_{4}\right)(96 \%)$, ferric chloride $\left(\mathrm{FeCl}_{3} \cdot 6 \mathrm{H}_{2} \mathrm{O}\right)$, nickel sulfate hexahydrate $\left(\mathrm{NiSO}_{4} \cdot 6 \mathrm{H}_{2} \mathrm{O}\right)$, ferrous sulfate heptahydrate $\left(\mathrm{FeSO}_{4} \cdot 7 \mathrm{H}_{2} \mathrm{O}\right)$, tert-butanol $\left(\mathrm{C}_{4} \mathrm{H}_{9} \mathrm{OH}, \mathrm{TBA}\right)$, 1, 10-phenanthroline monohydrate were all analytic reagent purchased from Sinopharm Chemical Reagent Co. Ltd., China. 4-chlorophenol (4-CP, >99\%), potassium biphthalate (KHP), dichloromethane $\left(\mathrm{CH}_{2} \mathrm{Cl}_{2}\right)$, and acetone $\left(\mathrm{C}_{3} \mathrm{H}_{6} \mathrm{O}\right)$ were obtained from Acros, Pittsburgh, PA. Terephthalic acid (TA) and 2-hydroxyterephthalic acid (TAOH) were purchased from Aladdin Chemistry Co. Ltd., China. Catalase (CAT), horseradish peroxidase (POD), and superoxide dismutase (SOD) were of analytic grade and received from Sigma-Aldrich (St. Louis, MO). High performance liquid chromatography (HPLC) grade acetonitrile were obtained from Merck. Methanol (HPLC grade) was purchased from Tedia Company, Inc., USA. All the chemicals were used as received without further purification. Deionized water 
was used throughout the experiments.

\subsection{Samples preparation}

The nZVIN with Ni/Fe molar ratio of $0.1: 1$ were synthesized by the reduction of $0.01 \mathrm{~mol} / \mathrm{L}$ of $\mathrm{FeCl}_{3} \cdot 6 \mathrm{H}_{2} \mathrm{O}$ and $0.001 \mathrm{~mol} / \mathrm{L}$ of $\mathrm{NiSO}_{4} \cdot 6 \mathrm{H}_{2} \mathrm{O}$ aqueous solution with 0.4 $\mathrm{mol} / \mathrm{L}$ of $\mathrm{NaBH}_{4}$ aqueous solution without any stirring. In a typical synthesis, $0.15 \mathrm{~g}$ of $\mathrm{FeCl}_{3} \cdot 6 \mathrm{H}_{2} \mathrm{O}$ and $0.0146 \mathrm{~g}$ of $\mathrm{NiSO}_{4} \cdot 6 \mathrm{H}_{2} \mathrm{O}$ were dissolved in $50 \mathrm{~mL}$ of deionized water to form solution $\mathrm{A}$, and $0.3 \mathrm{~g}$ of $\mathrm{NaBH}_{4}$ was added to $20 \mathrm{~mL}$ of deionized water to form solution B. Solution B was then dropped into solution A with a rate of 0.5 $\mathrm{mL} / \mathrm{s}$. The addition process was performed at ambient atmosphere without the protection of inert gases or vacuum atmosphere. During the addition, the solution was bubbled with plenty of gas with the addition of $\mathrm{NaBH}_{4}$ solution, accompanied by fluffy black precipitates that appeared on the surface of the solution. After the addition, the fluffy black precipitates were aged in the aqueous solution for 2 hours and then washed with deionized water and ethanol, finally dried under nitrogen flow for characterization. The nZVI was synthesized by the reduction of $0.01 \mathrm{~mol} / \mathrm{L}$ of $\mathrm{FeCl}_{3} \cdot 6 \mathrm{H}_{2} \mathrm{O}$ aqueous solution with $0.4 \mathrm{~mol} / \mathrm{L}$ of $\mathrm{NaBH}_{4}$ aqueous solution without any stirring in the absence of $\mathrm{NiSO}_{4} \cdot 6 \mathrm{H}_{2} \mathrm{O}$, as described previously [20]. The resulting samples in argon bubbled oxygen-free vials after the synthesis and weighted the sample as fast as possible for immediate use.

\subsection{Aerobic degradation of 4-CP}

The reactivity of nZVIN toward organic pollutant removal using air was evaluated with the aerobic degradation of 4-CP, which was carried out in $25 \mathrm{~mL}$ conical beakers 
at room temperature of $25{ }^{\circ} \mathrm{C}$. The initial $\mathrm{pH}$ of 4-CP solution was 6.0 without any adjusting. To initiate a reaction, $0.112 \mathrm{~g}$ of $\mathrm{nZVIN}$ was added to a $10 \mathrm{~mL}$ stock solution containing of $1.1 \mathrm{mmol} / \mathrm{L}$ of $4-\mathrm{CP}$ under air bubbling with a flow of 1.5 $\mathrm{L} / \mathrm{min}$. For comparison, the anaerobic degradation of $4-\mathrm{CP}$ was conducted under $\mathrm{Ar}$ gas bubbling with a flow of $1.5 \mathrm{~L} / \mathrm{min}$. The aerobic and anaerobic degradation of 4-CP in the presence of nZVI was also performed. Samples were collected at regular intervals using a $2 \mathrm{~mL}$ syringe and filtered immediately through a $0.22 \mu \mathrm{m}$ nylon syringe filter for high performance liquid chromatography analysis immediately. All the degradation experiments were triplicate.

\subsection{Anaerobic production of hydrogen}

Hydrogen production experiment was carried out in a $50 \mathrm{~mL}$ pyrex glass reactor. $0.1 \mathrm{~g}$ of nZVIN and/or nZVI was introduced into $30 \mathrm{~mL}$ of deaerated aqueous stock solution at an initial $\mathrm{pH}$ 5. The amount of $\mathrm{H}_{2}$ evolved was determined by a gas chromatograph (GC, SP-6800A, thermal conductivity detector, $5 \AA$ molecular sieve columns, and Ar carrier).

\subsection{Characterizations}

Scanning electron microscopy (SEM) was performed on a LEO 1450VP scanning electron microscope. Transmission electron microscope (TEM) was carried on a JEOL JEM-2010 electron microscope operating at $200 \mathrm{kV}$. The energy-filtered transmission electron microscope (EFTEM) was performed with JEM-ARM200F (GIF quantum 965). The nitrogen adsorption and desorption isotherms at $77 \mathrm{~K}$ were measured using a Micrometritics ASAP2010 system after samples were vacuum-dried at $473 \mathrm{~K}$ 
overnight. X-ray diffraction (XRD) patterns were obtained on a Bruker D8 Advance X-ray diffractometer with $\mathrm{Cu}$ Ka radiation $(\lambda=1.54178 \AA$ ). X-ray photoelectron spectroscopy (XPS) was recorded with a Kratos ASIS-HS X-ray photoelectron spectroscope equipped with a standard monochromatic source operated at 150W (15 $\mathrm{kV}, 10 \mathrm{~mA})$.

\subsection{Analysis}

The concentrations of 4-CP were analyzed by high performance liquid chromatograph (HPLC, LC-20A, Shimadzu, Japan) with an Agilent TC-C18 reverse phase column $(4.6 \times 150 \mathrm{~mm}, 5 \mu \mathrm{m})$ and ultraviolet detector setting at the wavelength of $279 \mathrm{~nm}$. The mobile phase was a mixture of acetonitrile and water with 1:1 volume ratio. The injection volume was $10 \mu \mathrm{L}$. Samples were analyzed at a flow rate of 0.5 $\mathrm{mL} / \mathrm{min}$.

The intermediates of 4-CP degradation were identified by gas chromatograph-mass spectrometry (GC-MS, Trace 1300-ISQ, Thermo Fisher, USA) equipped with a HP-5MS column $(0 \mathrm{~m} \times 0.25 \mathrm{~mm} \times 0.25 \mu \mathrm{m}$. Electron impact $(\mathrm{EI})$ was used as ionization technique with electron energy of $70 \mathrm{eV}$. Helium served as the carrier gas at a constant flow of $1.2 \mathrm{~mL} / \mathrm{min}$ (He, 99.99\%). Before GC-MS analysis, $20 \mathrm{~mL}$ of sample was extracted with equivalent dichloromethane for three times to obtain the extracts which were further dehydrated by anhydrous sodium sulfate. The dichloromethane was removed using a rotary evaporators. The residue was re-dissolved in $1 \mathrm{~mL}$ of acetone for the measurement.

Aqueous $\mathrm{Cl}^{-}$ions were detected by using an ion chromatograph (IC, Dionex LC20) 
equipped with an AS14 column; the mobile phase (a mixture of $1.8 \mathrm{mmoL} \mathrm{Na}_{2} \mathrm{CO}_{3}$ and $1.7 \mathrm{mmoL} \mathrm{NaHCO}_{3}$ ) was used at a flow rate of $1.20 \mathrm{~mL} / \mathrm{min}$. The volume of sample was $20 \mu \mathrm{L}$.

Hydrogen peroxide was analyzed using the N,N-diethyl- p-phenylenediamine (DPD) method developed by Bader et al [21]. Typically, $0.4 \mathrm{~mL}$ of phosphate buffer solution $(\mathrm{pH}=6)$ and $0.1 \mathrm{~mL}$ of $0.01 \mathrm{~mol} / \mathrm{L}$ bipyridine solution were premixed in a quartz cell, followed by the addition of $2 \mathrm{~mL}$ of the sample, $30 \mu \mathrm{L}$ of $1 \%$ DPD reagent in 0.1 $\mathrm{mol} / \mathrm{L} \mathrm{H}_{2} \mathrm{SO}_{4}$, and $30 \mu \mathrm{L}$ of horseradish peroxidase (POD) reagent sequentially. The absorbance at $551 \mathrm{~nm}$ was measured using a UV-vis spectrophotometer (U-3310, HITACHI) after the addition of the POD.

Terephthalic acid (TA) was used as the fluorescent probe for the detection of hydroxyl radicals. 2-hydroxyterephthalic acid $(\mathrm{TAOH})$, which is the fluorescent product of the reaction of TA with $\bullet \mathrm{OH}$, has a strong fluorescent emission around 426 $\mathrm{nm}$ when excited at $312 \mathrm{~nm}$ [22]. Fluorescence spectra of the supernatant liquid were measured with a fluorescence spectrophotometer (Cary Eclipse Fluorescent Spectrometer, FL1008M018). In a typical process, an aqueous solution with 0.01 $\mathrm{mol} / \mathrm{L}$ of $\mathrm{NaOH}$ and $0.5 \mathrm{mmol} / \mathrm{L}$ of TA was prepared and then reacted with $2 \mathrm{~mL}$ of sample solution for $10 \mathrm{~min}$ for the subsequent fluorescence measurements. The amount of produced TAOH was determined by the fluorescence intensity.

The concentrations of ferrous ion in solution were measured by a modified 1, 10-phenanthroline method using a UV-vis spectrophotometer (U-3310, HITACHI) [23]. In a typical process, aqueous samples were added to $1 \mathrm{~mL}$ of 1 , 10-phenanthroline ( $2 \mathrm{~g} / \mathrm{L}$ ) in a $1 \mathrm{~cm}$ quartz cell, deionized water was added to make the final volume of $3 \mathrm{~mL}$. The absorbance was measured at $\lambda=510 \mathrm{~nm}$, which is the maximal adsorption of Fe(II)-1,10-phenanthroline complex. The concentration of total 
soluble nickel ions and iron ions $\left(\mathrm{Fe}^{\mathrm{n}+}\right)$ in the solution were measured by atom absorption spectrometry (AA-6300, Shimadzu).

\subsection{Computational details}

The structure of 4-CP was fully optimized at the B3lyp/6-311+G(d) level of theory using the Gaussian 09 package with tight SCF convergence. The solvent effect was taken into account by using the implicit solvent model. The data was further broadened by Multiwfn 3.3.8 to obtain the Hirshfeld charge [24], the checkpoint file from the above Gaussian calculations was used as the input file.

\section{Results and discussion}

\subsection{Characterizations}

The morphology of the resulting samples was investigated by SEM and TEM. As shown in Figure 1, both the as-prepared nZVI and nZVIN were nanoparticles with spherical shape in the size of about $100 \mathrm{~nm}$ and formed chain-like clusters via magnetic and electrostatic interactions (Figure 1a, 1d). TEM results confirmed that both nZVI and nZVIN have similar spherical shape in which the diameters of the nanospheres were in the range of $80-150 \mathrm{~nm}$ (Figure 1b, 1c, 1e, and 1f). The contrast between the gray edge and the dark center of the samples was easily observed, confirming the core-shell structure of the metal core surrounded by a layer of metal oxide shell, this result is in constant with our previous report [19]. Moreover, the elements distribution of nZVI and nZVIN were investigated by EFTEM and element mapping analysis (Figure 2). The EFTEM element mapping analysis indicated that both Fe (Figure 2b) and $\mathrm{O}$ (Figure 2c) elements existed in nZVI. On contrast, besides the existence of $\mathrm{Fe}$ and $\mathrm{O}$ elements (Figure 2e and 2f), Ni element was distributed evenly on the sample of nZVIN (Figure 2g), indicating the successful nickel metal 
incorporation and the formation of bimetallic Fe-Ni nanoparticles.

$\mathrm{N}_{2}$ adsorption-desorption analysis was performed to determine the specific surface area of the resulting nZVI and nZVIN nanoparticles (Figure 3a). The BET surface area of the nZVI and nZVIN was found to be 29.03 and $20.61 \mathrm{~m}^{2} / \mathrm{g}$ respectively. X-ray diffraction was used to characterize the phase structure of the as-prepared nZVI and nZVIN (Figure 3b). The XRD patterns of the nZVI and nZVIN showed main diffraction peaks at $2 \theta=44.7^{\circ}$ and $2 \theta=44.6^{\circ}$, which can be indexed to the (110) plane of cubic Fe (PDF no. 87-721) and the iron nickel (PDF no. 3-1044) respectively. A weak peak at $2 \theta=35.6^{\circ}$ which was related to $\mathrm{Fe}_{2} \mathrm{O}_{3}$ (PDF no. 73-603) could be observed in nZVI due to the reaction of Fe and molecular oxygen or water during the synthesis. It should be noticed that the peak intensities of the bimetallic nZVIN samples decrease with the nickel metal incorporation, suggesting that a less ordered structure was formed in nZVIN. Additionally, the (100) peaks for the nZVIN samples shifted slightly to lower $2 \theta$ values, indicating that after incorporation the size got slightly bigger, this result agreed with the BET result.

The chemical compositions of nZVI and nZVIN were characterized with XPS (Figure 4). The survey XPS spectra revealed that carbon, oxygen, and iron element co-existed on the surface of both samples, nickel element was found only on nZVIN (Figure 4a). The surface carbon is likely from the inadvertent exposure to atmospheric carbon dioxide and potentially small hydrocarbon molecules in air, water, and on the glassware during the sample preparation and transfer [25]. Detailed Fe 2p survey were investigated (Figure 4b). As per the prepared nZVI, the peaks around $710.8 \mathrm{eV}$ and $723.4 \mathrm{eV}$ were corresponded to the binding energies of $2 \mathrm{p}_{3 / 2}$ and $2 \mathrm{p}_{1 / 2}$ of $\mathrm{Fe}(\mathrm{III})$ in $\mathrm{Fe}_{2} \mathrm{O}_{3}$. The shoulder at $719.6 \mathrm{eV}$ is likely the satellite $2 \mathrm{p}_{1 / 2}$ for zero valent iron. While for the nZVIN sample, the peaks around $709.5 \mathrm{eV}$ and $723.1 \mathrm{eV}$ were ascribed to the 
binding energies of $2 \mathrm{p}_{3 / 2}$ and $2 \mathrm{p}_{1 / 2}$ of $\mathrm{Fe}$ (II) in $\mathrm{FeO}$, and peaks around $707 \mathrm{eV}$ and $720 \mathrm{eV}$ correspond to the binding energies of $2 \mathrm{p}_{3 / 2}$ and $2 \mathrm{p}_{1 / 2}$ of zero valent iron. The high resolution XPS spectra of $\mathrm{Ni} 2 \mathrm{p}$ could be fitted into two peaks at $852.7 \mathrm{eV}$ and $870.2 \mathrm{eV}$, which are the characteristics of $\mathrm{Ni} 2 \mathrm{p}_{1 / 2}$ and $\mathrm{Ni} 2 \mathrm{p}_{3 / 2}$ of metallic nickel, respectively (Figure 4c).

\subsection{Aerobic degradation of 4-CP}

The aerobic and anaerobic degradation of 4-CP with nZVI and/or nZVIN were compared at neutral $\mathrm{pH} 6.0$ at $25{ }^{\circ} \mathrm{C}$. As shown in Figure 5a, the degradation of 4-CP was negligible in the nZVI/Ar system, while $35 \%$ of 4-CP was aerobically degraded with nZVI/Air in $4 \mathrm{~h}$. However, the 4-CP removal efficiencies in $4 \mathrm{~h}$ reached $40 \%$ and $89 \%$ in the nZVIN/Ar and nZVIN/Air systems respectively. Obviously, oxygen played a vital role in the 4-CP degradation, and the nZVIN leaded to an enhancement in degradation of 4-CP compared with nZVI. The aerobic 4-CP degradation processes were found to follow pseudo-first order kinetics within $4 \mathrm{~h}$ (Figure 5b), the 4-CP degradation rate constants were $0.111,0.123$, and $0.563 \mathrm{~h}^{-1}$ for the nZVI/Air, nZVIN/Ar, and nZVIN/Air systems respectively. We found that nZVIN could induce the 4-CP degradation with or without oxygen, the rate constant in the presence of oxygen was 4.6 times that in the absence of oxygen. As expected, the aerobic 4-CP degradation rate in the nZVIN/Air system was nearly 5.1 times that in the nZVI/Air system, the nickel incorporated in the bimetal could greatly enhance the aerobic 4-CP degradation with nZVIN. This could be attributed to the galvanic contact between nickel $\left(\mathrm{Ni} / \mathrm{Ni}^{2+}(0.257)\right)$ and iron $\left(\mathrm{Fe} / \mathrm{Fe}^{2+}(0.447)\right)$ [8], which induced a large electrochemical potential difference driving iron oxidation.

In the anaerobic system, 4-CP could not degrade over nZVI/Ar in the absence of oxygen, however, nZVIN/Ar could induce $40 \%$ of 4-CP degradation. This might be 
ascribed to the direct reduction from atomic hydrogen adsorbed on the reductant surface $[9,26]$. We therefore investigated the hydrogen evolution through the reduction of proton (water) by nZVI and nZVIN. As showed in Figure 6, only 6.5 $\mu \mathrm{mol}$ of $\mathrm{H}_{2}$ was generated over the nZVI, while a much higher of $44.6 \mu \mathrm{mol} \mathrm{H}_{2}$ was produced with the nZVIN. Obviously, the evolution rate of hydrogen over the nZVIN was more than that over the nZVI at neutral $\mathrm{pH}$. Zero-valent iron can in-situ reduce water reduction to gaseous $\mathrm{H}_{2}$ (Eq. 1), the chem-adsorbed $\mathrm{H}_{2}$ on the bimetal surface was further dissociated to active $\mathrm{H}$ atom as nickel is a well-known hydrogenation catalyst (Eq. 2), which is thought be a competitive reaction of 4-CP degradation (Eq. 3). This result confirmed that $\mathrm{Ni}$ could increase the hydrogen evolution over zero valent iron. Consequently, the enhanced production of $\mathrm{H}$ from nZVIN might lead to effective $\mathrm{H}$ may be responsible for the 4-CP degradation with nZVIN.

$$
\begin{aligned}
& \mathrm{Fe}^{0}+2 \mathrm{H}^{+} \rightarrow \mathrm{Fe}^{2+}+\mathrm{H}_{2(\mathrm{~g})} \\
& \mathrm{H}_{2(\mathrm{~g})} \stackrel{\mathrm{Ni}}{\longrightarrow} 2 \mathrm{H} \\
& \mathrm{H}+4-\mathrm{CP} \rightarrow \text { phenol }+\mathrm{Cl}^{-}
\end{aligned}
$$

GC-MS and HLPC analysis was employed to investigate the intermediates of 4-CP degradation during the nZVI/Air and nZVIN/Air systems. As shown in Figure 7a, the oxidative intermediates of hydroquinone and p-benzoquinone of 4-CP due to the cleavage of bonds between the chlorine and carbon atom in the benzene ring by $\bullet \mathrm{OH}$ radicals were detected in the nZVI/Air system, on contrast, mainly reductive intermediates of phenol from partial direct dechlorination of $4-\mathrm{CP}$ by $\bullet \mathrm{O}_{2}{ }^{-}$radicals were found in the nZVIN/Air, indicating that the presence of nickel could alter the oxidative process with nZVI to the reductive pathway over nZVIN during the aerobic 4-CP degradation. In addition, negligible phenol was detected in the absence of oxygen, however, the amount of phenol intermediates increase with prolonging 
reaction time and then decrease during the nZVIN/Air system (Figure 7b), implying that the phenol intermediates could be further oxidized in the nZVIN/Air process. GC-MS results of the intermediate products generated during the degradation of 4-CP were evidenced by p-benzoquinone, phenol, and hydroquinone (Figure 7c, 7d, 7e, and $7 f)$.

Additionally, we analyzed the production of ROS in these two systems with adding different scavengers (tertiary butanol for $\bullet \mathrm{OH}$, SOD for $\bullet \mathrm{O}_{2}{ }^{-}$, CAT for $\mathrm{H}_{2} \mathrm{O}_{2}$ ). As shown in Figures 8, the addition of tertiary butanol (TBA) could significantly inhibit the aerobic 4-CP degradation in the nZVI/Air systems, however, a slighter inhibition was observed in the presence of TBA in the nZVIN/Air system. This result revealed the major oxidative species for the 4-CP degradation in the nZVI/Air system were -OH. Several researchers have proposed possible reaction mechanisms to explain the generation of $\bullet \mathrm{OH}$ in aerobic ZVI systems [19]. It was hypothesized that the ZVI transfers electrons to $\mathrm{O}_{2}$ to produce $\mathrm{H}_{2} \mathrm{O}_{2}$ and $\mathrm{Fe}(\mathrm{II})$, which resulted in the formation of $\bullet \mathrm{OH}$ through Fenton reactions. Interestingly, we found that $\bullet \mathrm{O}_{2}{ }^{-}$played different roles in the nZVI/Air and nZVIN/Air systems, as the 4-CP degradation efficiency decreased sharply after the addition of SOD in the nZVIN/Air system, but slightly decreased in the case of nZVI/Air process. The SOD induced 4-CP degradation efficiency decrease suggested that $\cdot \mathrm{O}_{2}{ }^{-}$might directly contribute to the reductive dechlorination of $4-\mathrm{CP}$ in the nZVIN/Air system. If $\bullet \mathrm{O}_{2}{ }^{-}$did not participate in the 4-CP degradation directly in the system, its disproportionation into $\mathrm{H}_{2} \mathrm{O}_{2}$ could be accelerated by $\mathrm{SOD}$, resulting in more $\cdot \mathrm{OH}$ generation via Fenton reaction for the enhanced 4-CP degradation. We therefore conclude that $\bullet \mathrm{O}_{2}{ }^{-}$is directly involved in the reductive dechlorination of 4-CP in the nZVIN/Air system, but indirectly contribute to the oxidative degradation of $4-\mathrm{CP}$ via its transformation into $\cdot \mathrm{OH}$ in the nZVI/Air 
system.

The TA fluorescent probe method was then used to detect the $\bullet \mathrm{OH}$ production in the nZVI/Air and nZVIN/Air systems (Figure 9a). We found the amount of 2-hydroxyterephthalic acid in the two systems increased within $4 \mathrm{~h}$, suggesting its continuous generation of $\bullet \mathrm{OH}$. As for the nZVI/Air system, it generated much more 2-hydroxyterephthalic acid than that in the nZVIN/Air system. As shown in Figure 9b, the $\mathrm{H}_{2} \mathrm{O}_{2}$ generation curve of the two systems was quite different, the amount of $\mathrm{H}_{2} \mathrm{O}_{2}$ in the nZVIN/Air system was more than that in the nZVI/Air process. Furthermore, the decomposition of $\mathrm{H}_{2} \mathrm{O}_{2}$ in the nZVI/Air system was faster than that in the nZVIN/Air system (Figure 10), implying that the bimetallic nZVIN has lower activity of $\mathrm{H}_{2} \mathrm{O}_{2}$ activation [27].

$$
\begin{aligned}
& \mathrm{Fe}^{0}+\mathrm{O}_{2}+2 \mathrm{H}^{+} \rightarrow \mathrm{Fe}^{2+}+\mathrm{H}_{2} \mathrm{O}_{2} \\
& \mathrm{Fe}^{2+}+\mathrm{H}_{2} \mathrm{O}_{2} \rightarrow \mathrm{Fe}^{3+}+\cdot \mathrm{OH}+\mathrm{OH}^{-} \\
& \mathrm{Fe}^{2+}+\mathrm{O}_{2} \rightarrow \mathrm{Fe}^{3+}+\cdot \mathrm{O}_{2}^{-} \\
& \mathrm{Ni}^{0}+2 \mathrm{O}_{2} \rightarrow \mathrm{Ni}^{2+}+2 \cdot \mathrm{O}_{2}^{-} \\
& \mathrm{Ni}^{2+}+\mathrm{Fe}^{0} \rightarrow \mathrm{Fe}^{2+}+\mathrm{Ni}^{0} \\
& \mathrm{Ni}^{0}+2 \mathrm{Fe}^{3+} \rightarrow \mathrm{Ni}^{2+}+2 \mathrm{Fe}^{2+}
\end{aligned}
$$

To figure out the role of nickel on the enhanced aerobic 4-CP degradation with nZVIN, we monitored the concentrations of $\mathrm{Ni}(\mathrm{II})$ and $\mathrm{Fe}(\mathrm{II})$ during the nZVIN/Air process (Figure 11). It was found that the concentration of $\mathrm{Ni}(\mathrm{II})$ increased with prolonging reaction time, $22.5 \mathrm{mg} / \mathrm{L}$ of $\mathrm{Ni}(\mathrm{II})$ was released into aqueous solution after $4 \mathrm{~h}$ (Figure 11a). This might be ascribed to the reaction of $\mathrm{Ni}$ and oxygen, contributing to the one-electron reduction of $\mathrm{O}_{2}$ to $\cdot \mathrm{O}_{2}^{-}$, as reported by Liu (Eqs. 7-8) [28]. As shown in Figure 11b, less Fe(II) was released in the nZVIN/Air system, indicating 
that the presence of nickel could significantly inhibit the release of Fe(II). The oxidation of $\mathrm{Fe}^{0}$ to ferrous ions was related to the two-electron molecular oxygen reduction process (Eq. 4). Standard redox potential of $\mathrm{Ni}^{2+} / \mathrm{Ni}^{0}\left(\mathrm{E}^{0} \mathrm{Ni}^{2+} / \mathrm{Ni}(\mathrm{s})=-0.257\right.$ $\mathrm{V}$ at $298 \mathrm{~K})$ is higher than that of $\mathrm{Fe}^{2+} / \mathrm{Fe}^{0}\left(\mathrm{E}^{0} \mathrm{Fe}^{2+} / \mathrm{Fe}(\mathrm{s})=-0.447 \mathrm{~V}\right.$ at $\left.298 \mathrm{~K}\right)$, suggesting that $\mathrm{Ni}(\mathrm{II})$ can be reduced to $\mathrm{Ni}(0)$ by nZVI. In the nZVIN/Air system, $\mathrm{Fe}(\mathrm{II})$ was released to bulk aqueous solution and reacted with $\mathrm{O}_{2}$ to generate $\mathrm{Fe}$ (III) (Eq. 6), which could be subsequently reduced to $\mathrm{Fe}(\mathrm{II})$ by $\mathrm{Ni}(0)$, resulting in $\mathrm{Fe}(\mathrm{II}) / \mathrm{Fe}(\mathrm{III})$ cycles (Eq. 9). This is the reason why the concentration of ferrous ions and ferric ions in the nZVIN/air system is much lower than that in nZVI/air system. We further monitored the concentration variation of released chloride ions during the aerobic 4-CP degradation (Figure 11c). The nZVIN/Air system exhibited higher 4-CP degradation and dechlorination efficiencies than the nZVI/Air counterpart. We mainly attributed this to the reductive dechlorination by $\cdot \mathrm{O}_{2}{ }^{-}$, besides the role of active $\mathrm{H}$ and the oxidative dechlorination with $\bullet \mathrm{OH}$. In addition, we found the amount of small molecule acid (formic acid, $\mathrm{HCOOH}$ ) generated in the nZVI/Air systems was much more than that in the nZVIN/Air system (Figure 11d), confirming the 4-CP degradation pathways were dependent on the generated reactive oxygen species in these two systems. This was consistent with the result that more hydroxyl radicals generated in the nZVI/Air system could break down the benzene ring of 4-CP easily compared to the nZVIN/Air system.

In theory, $\bullet \mathrm{O}_{2}{ }^{-}$and $\bullet \mathrm{H}$ were thought to be excellent nucleophilic regents, while $\bullet \mathrm{OH}$ was thought to be an electrophilic regents for degradation of organic pollutants. For electrophilic attacks, the site with the most negative charge is preferred, and for nucleophilic attacks, the site with the most positive charge is selected [29-32]. Hirshfeld charge analysis was used to unravel the selectivity of $\bullet \mathrm{O}_{2}{ }^{-}$for degradation of 
4-CP in the nZVIN/Air system (Figure 12). The analysis results showed that C3 was the one with the most positive charges among all of the six carbons in the benzene ring of 4-CP, indicating that the $\mathrm{C}-\mathrm{Cl}$ bond of 4-CP molecules is easy to be attacked by $\cdot \mathrm{O}_{2}{ }^{-}$and $\bullet \mathrm{H}$ nucleophilically, this was evidenced by our experiment results.

\subsection{Mechanism of the enhanced degradation of 4-CP with nZVIN}

On the basis of the results and analyses, we proposed the mechanism for the 4-CP degradation in the nZVI/Air and nZVIN/Air systems (Scheme 1). In the nZVI/Air system, the appearance of hydroquinone and p-benzoquinone suggested the oxidative attack of $\mathrm{C}-\mathrm{Cl}$ bonds of $4-\mathrm{CP}$ by $\cdot \mathrm{OH}$, then these oxidative intermediates were decomposed to small molecule acids (formic acid), and finally 4-CP might be mineralized into $\mathrm{CO}_{2}$ and $\mathrm{H}_{2} \mathrm{O}$ under the attack of $\bullet \mathrm{OH}$. In the nZVIN/Air system, addition of nickel into nZVI stimulate the recycle of $\mathrm{Fe}(\mathrm{III}) / \mathrm{Fe}(\mathrm{II})$, and $\mathrm{Fe}(\mathrm{II})$ and $\mathrm{Ni}(0)$ could favor the process of one-electron reduction of $\mathrm{O}_{2}$ to $\bullet \mathrm{O}_{2}{ }^{-}$. The $\cdot \mathrm{O}_{2}{ }^{-}$induced reductive dechlorination of 4-CP was overwhelming, resulting in the generation of phenol. Simultaneously, active $\mathrm{H}$ and $\bullet \mathrm{OH}$ contributed to the dechlorination of 4-CP to generate phenol and hydroquinone.

\section{Conclusions}

In summary, the bimetallic iron-nickel nanoparticles (nZVIN) possessed an enhanced performance in comparison with nanoscale zero-valent iron (nZVI) on aerobic degradation of 4-CP. The primary intermediates of 4-CP found in the nZVIN/Air system were phenol via the direct dechlorination by superoxide radicals, accompanying with the formation of chloride ions. The presence of nickel could significantly accelerate the production of $\bullet \mathrm{O}_{2}^{-}$radicals which are the main species responsible for the degradation of $4-\mathrm{CP}$ in the nZVIN/Air system. These findings 
provide new insights for deep understanding of nickel on the molecular oxygen activation with nZVI for the degradation of 4-CP and possibly other environmental pollutants.

Acknowledgements. This work was supported by The National Key Research and Development Program of China (2016YFA0203000), National Natural Science Funds for Distinguished Young Scholars (21425728), National Science Foundation of China (21477044), Key Project of Natural Science Foundation of Hubei Province (2013CFA114), Self-Determined Research Funds of CCNU from the Colleges' Basic Research and Operation of MOE (CCNU14Z01001 and CCNU14KFY002), the Fundamental Research Funds for the Central Universities (CCNU16A02029), and the Excellent Doctoral Dissertation Cultivation Grant from Central China Normal University (2016YBZZ016).

\section{References}

[1] B. Gu, T. J. Phelps, L. Liang, M. J. Dickey, Y. Roh, B.L. Kinsall, A.V. Palumbo, K. Jacobs, Biogeochemical dynamics in zero-valent iron columns: Implications for permeable reactive barriers. Environ. Sci. Technol. 1999; 332: 170-2177.

[2] W. X. Zhang, Nanoscale iron particles for environmental remediation: An overview, J. Nanoparticle Res. 2003; 5: 323-332.

[3] S. M. Ponder, J. G. Darab, T. E. Mallouk, Remediation of $\mathrm{Cr}(\mathrm{VI})$ and $\mathrm{Pb}(\mathrm{II})$ aqueous solutions using supported nanoscale zero-valent iron. Environ. Sci. Technol. 2000; 34: 2564-2569.

[4] A. Agrawal, P. G. Tratnyek, Reduction of nitro aromatic compounds by zero-valent iron metal. Environ. Sci. Technol. 1995; 30: 153-160.

[5] L. J. Matheson, P. G. Tratnyek, Reductive dehalogenation of chlorinated methanes 
by iron metal. Environ. Sci. Technol. 1994; 28: 2045-2053.

[6] G. D. Fang, D. M. Zhou, D. D. Dionysiou, Superoxide mediated production of hydroxyl radicals by magnetite nanoparticles: Demonstration in the degradation of 2-chlorobiphenyl. J. Hazard. Mater. 2013; 250-251: 68-75.

[7] A. D. Brokare, W. Choi, Zero-valent aluminum for oxidative degradation of aqueous organic pollutants. Environ. Sci. Technol. 2009; 43: 7130-7135.

[8] C. L. Chun, D. R. Baer, D. W. Matson, J. E. Amonette, R. L. Penn, Characterization and reactivity of iron nanoparticles prepared with added $\mathrm{Cu}, \mathrm{Pd}$, and Ni. Environ. Sci. Technol. 2010; 44: 5079-5085.

[9] D. M. Cwiertny, S. J. Bransfield, A. L. Roberts, Influence of the oxidizing species on the reactivity of iron-based bimetallic reductants. Environ. Sci. Technol. 2007; 41: 3734-3740.

[10] D. He, C. J. Miller, T. D. Waite, Fenton-like zero-valent silver nanoparticle-mediated hydroxyl radical production. J. Catal. 2014; 317: 198-205.

[11] W. Yan, A. A. Herzing, X. Q. Li, C. J. Kiely, W. X. Zhang, Structural evolution of Pd-doped nanoscale zero-valent iron (nZVI) in aqueous media and implications for particle aging and reactivity. Environ. Sci. Technol. 2010; 44: 4288-4294.

[12] Y. Zhuang, S. Ahn, A. L. Seyfferth, Y. Masue-Slowey, S. Fendorf, R. G. Luthy, Dehalogenation of polybrominated diphenyl ethers and polychlorinated biphenyl by bimetallic, impregnated, and nanoscale zerovalent iron. Environ. Sci. Technol. 2011; 45: 4896-4903.

[13] W. H. Zhang, X. Quan, Z. Y. Zhang, Catalytic reductive dechlorination of p-chlorophenol in water using Ni/Fe nanoscale particles, J. Environ. Sci. 2007; 19: 362-366.

[14] R. Cheng, W. Zhou, J. L. Wang, D. Qi, L. Guo, W. X. Zhang, Y. Qian, 
Dechlorination of pentachlorophenol using nanoscale Fe/Ni particles: Role of nano-Ni and its size effect. J. Hazard. Mater. 2010; 180: 79-85.

[15] H. Tian, J. Li, Z. Mu, L. Li, Z. Hao, Effect of pH on DDT degradation in aqueous solution using bimetallic Ni/Fe nanoparticles. Separation Purification Tech. 2009; 66: 84-89.

[16] F. Xu, S. Deng, J. Xu, W. Zhang, M. Wu, B. Wang, J. Huang, G. Yu, Highly active and stable $\mathrm{Ni}-\mathrm{Fe}$ bimetal prepared by ball milling for catalytic hydrodechlorination of 4-Chlorophenol. Environ. Sci. Technol. 2012; 46: 4576-4582.

[17] C. Lee, D. L. Sedlak, Enhanced formation of oxidants from bimetallic nickel-iron nanoparticles in the presence of oxygen. Environ. Sci. Technol. 2008; 42: 8528-8533. [18] M. Vallejo, M. F. San Román, I. Ortiz, Quantitative assessment of the formation of polychlorinated derivatives, $\mathrm{PCDD} / \mathrm{Fs}$, in the electrochemical oxidation of 2-chlorophenol as function of the electrolyte type. Environ. Sci. Technol. 2013; 47: 12400-12408.

[19] Z. Ai, Z. Gao, L. Zhang, W. He, J. J. Yin, Core-shell structure dependent reactivity of $\mathrm{Fe} @ \mathrm{Fe}_{2} \mathrm{O}_{3}$ nanowires on aerobic degradation of 4-chlorophenol. Environ. Sci. Technol. 2013; 47: 5344-5352.

[20] Z. Ai, L. Lu, J. Li, L. Zhang, J. Qiu, M. Wu, Fe@ $\mathrm{Fe}_{2} \mathrm{O}_{3}$ core-shell nanowires as iron reagent. 1. Efficient degradation of rhodamine. J. Phy. Chem. C. 2007; 111: 4087-4093.

[21] H. Bader, V. Sturzenegger, J. Hoigné, Photometric method for the determination of low concentrations of hydrogen peroxide by the peroxidase catalyzed oxidation of N, N-diethyl-p-phenylenediamine (DPD). Water Res. 1988; 22: 1109-1115.

[22] T. Hirakawa, Y. Nosaka, Properties of $\mathrm{O}_{2}{ }^{-}$and $\mathrm{OH} \cdot$ formed in $\mathrm{TiO}_{2}$ aqueous suspensions by photocatalytic reaction and the influence of $\mathrm{H}_{2} \mathrm{O}_{2}$ and some ions. 
Langmuir. 2002; 18: 3247-3254.

[23] A. E. Harvey, J. A. Smart, E. S. Amis, Simultaneous spectrophotometric determination of iron(II) and total iron with 1,10-phenanthroline, Anal. Chem. 1955; 27: 26-29.

[24] T. Lu, F. Chen, Quantitative analysis of molecular surface based on improved Marching Tetrahedra algorithm. J. Mol. Graphics Model. 2012; 38: 314-323.

[25] X. Q. Li, W. X. Zhang, Sequestration of metal cations with zerovalent iron nanoparticles-A study with high resolution X-ray photoelectron spectroscopy (HR-XPS). J. Phy. Chem. C. 2007; 111: 6939-6946.

[26] D. M. Cwiertny, S. J. Bransfield, K. J. T. Livi, D. H. Fairbrother, A. L. Roberts, Exploring the influence of granular iron additives on 1,1,1-trichloroethane reduction. Environ. Sci. Technol. 2006; 40: 6837-6843.

[27] C. Keenan, D. L. Sedlak, Enhanced formation of oxidants from bimetallic Nickel-iron nanoparticles in the presence of oxygen. Environ. Sci. Technol. 2008; 42: 6936-6941.

[28] W. Liu, Z. Ai, L. Zhang, Design of a neutral three-dimensional electro-Fenton system with foam nickel as particle electrodes for wastewater treatment. J. Hazard. Mater. 2012; 243: 257-264.

[29] S. Liu, C. Rong, T. Lu, Information conservation principle determines electrophilicity, nucleophilicity, and regioselectivity. J. Phy. Chem. A. 2014; 118: 3698-3704.

[30] V. S. Bryantsev, V. Giordani, W. Walker, M. Blanco, S. Zecevic, K. Sasaki, J. Uddin, D. Addison, G. V. Chase, Predicting solvent stability in aprotic electrolyte Li-air Batteries: Nucleophilic substitution by the superoxide anion radical $\left(\mathrm{O}_{2} \bullet^{-}\right)$. J. Phy. Chem. A. 2011; 115: 12399-12409. 
[31] M. Mạkosza, K. Wojciechowski, Nucleophilic substitution of hydrogen in heterocyclic chemistry. Chem. Rev. 2004; 104: 2631-2666.

[32] M. P. DeMatteo, J. S. Poole, X. Shi, R. Sachdeva, P. G. Hatcher, C. M. Hadad, M. S. Platz, On the electrophilicity of hydroxyl radical: A laser flash photolysis and computational study. J. Am. Chem. Soc. 2005; 127: 7094-7109. 


\section{Figure Captions}

Figure 1. SEM image (a), and TEM images of the prepared nZVI (b, c); SEM image (d), and TEM images of the prepared nZVIN (e, f).

Figure 2. EFTEM image (a) and EFTEM element mapping images of the prepared nZVI (b, c); EFTEM image (d) and EFTEM element mapping images of the prepared nZVIN (e, f, g).

Figure 3. Nitrogen adsorption-desorption isotherm (a); and XRD patterns of the resulting nZVI and nZVIN samples (b).

Figure 4. XPS wide-scan survey of the prepared nZVI and nZVIN (a); XPS Fe 2p survey of nZVI and nZVIN (b); and XPS Ni2p survey of nZVIN (c).

Figure 5. The temporal concentration change of $4-\mathrm{CP}$ as a function of reaction time during the aerobic degradation of $4-\mathrm{CP}$ in different systems (a); and plots of $\ln \left(\mathrm{C} / \mathrm{C}_{0}\right)$ versus time (b).

Figure 6. The temporal concentration change of hydrogen evolution over the as-prepared nZVI and nZVIN as a function of reaction time.

Figure 7. HPLC spectra (a); the amount of phenol generation during the nZVIN/Ar, and nZVIN/Air systems (b); GC-MS spectra of 4-CP (c), hydroquinone (d), 1,4-Benzoquinone (e), and phenol (f), reprentatively.

Figure 8. Time profiles of the 4-CP degradation in the nZVI/Air system (a), and the nZVIN/Air system (b) in the presence or absence of ROS scavengers.

Figure 9. Measurement of $\bullet \mathrm{OH}(\mathrm{a})$, and $\mathrm{H}_{2} \mathrm{O}_{2}$ (b) in the nZVI/Air and nZVIN/Air systems.

Figure 10. The decomposition of $\mathrm{H}_{2} \mathrm{O}_{2}$ in the nZVI/Air and nZVIN/Air systems.

Figure 11. Variation of nickel ions (a); ferrous ions and total iron (b); chloride ions (c); andformic acid (d) concentrations in different systems during the 4-CP degradation. 
Figure 12. Hirshfeld charges for six carbons of 4-CP molecule.

Scheme 1. The possible 4-CP degradation mechanism in the nZVIN/Air system. 


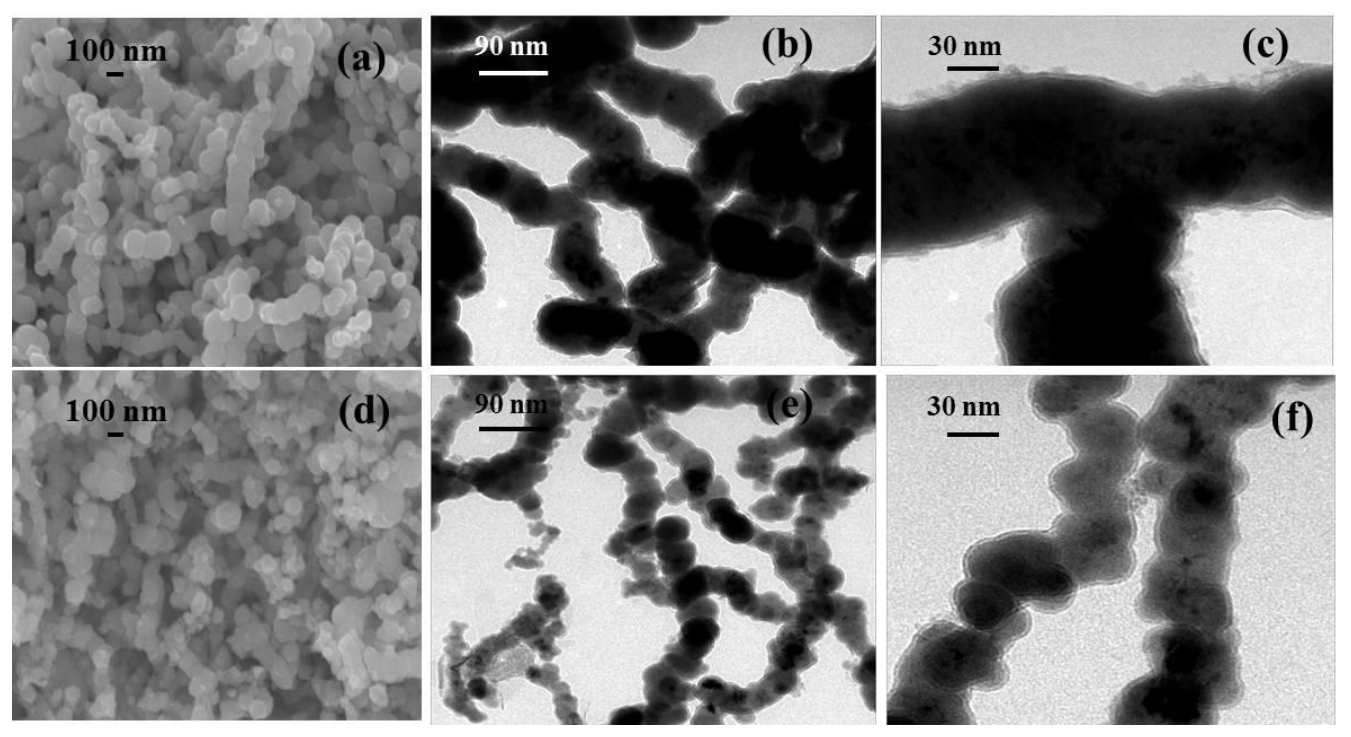

Figure 1. SEM image (a), and TEM images of the prepared nZVI (b, c); SEM image (d), and TEM images of the prepared nZVIN (e, f).

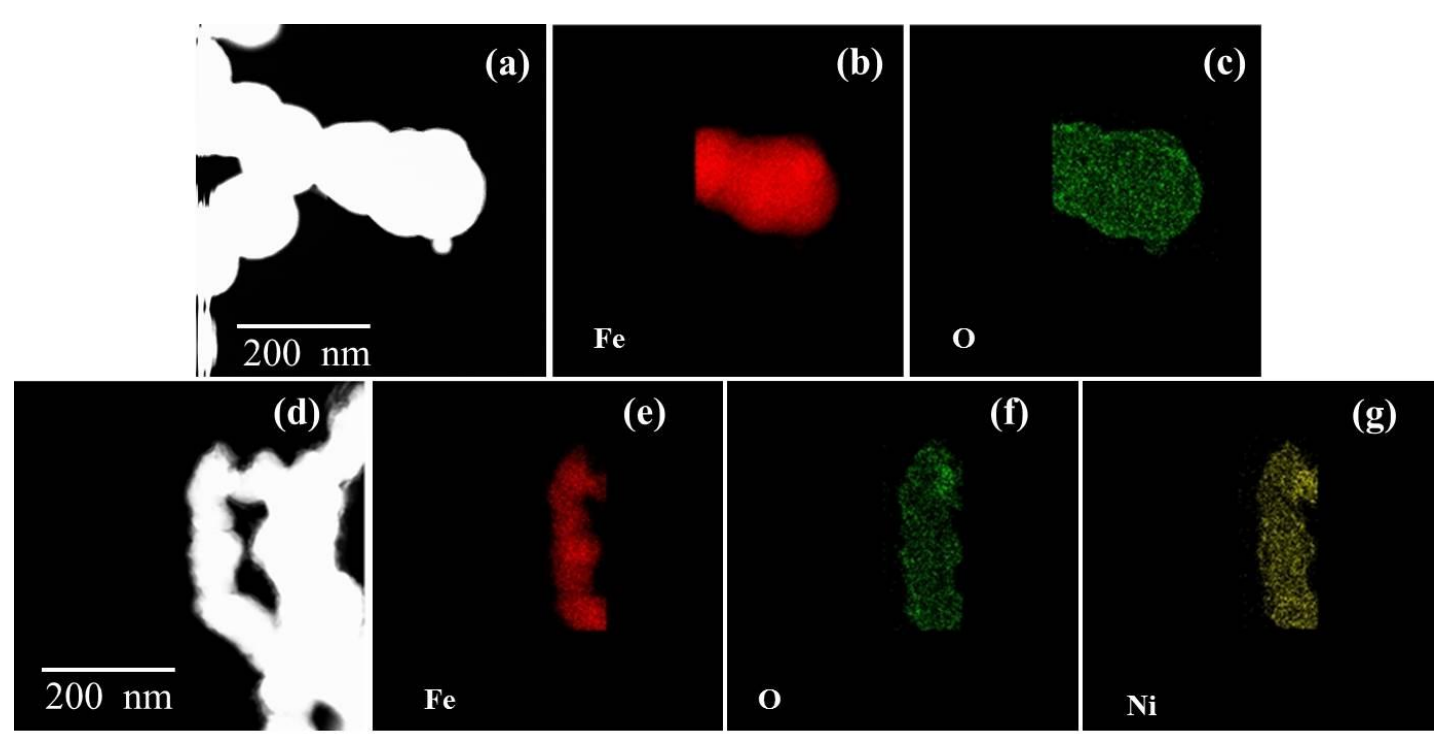

Figure 2. EFTEM image (a) and EFTEM element mapping images of the prepared nZVI (b, c); EFTEM image (d) and EFTEM element mapping images of the prepared $\operatorname{nZVIN}(e, f, g)$. 

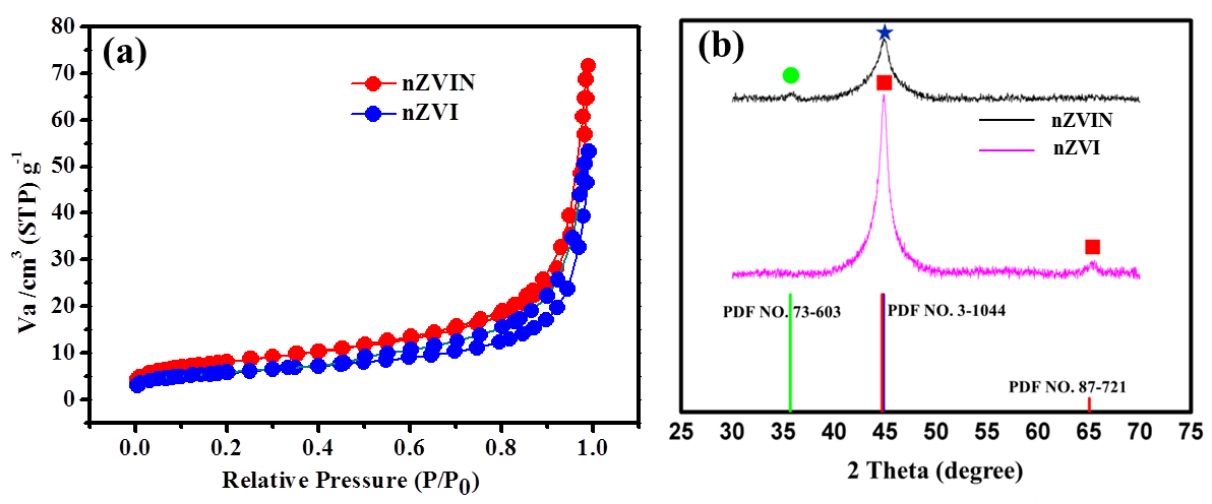

Figure 3. Nitrogen adsorption-desorption isotherm (a); and XRD patterns of the resulting nZVI and nZVIN samples (the green cycle, red square, and blue star were corresponding to $\mathrm{Fe}_{2} \mathrm{O}_{3}$, nZVIN and nZVI, respectively) (b).

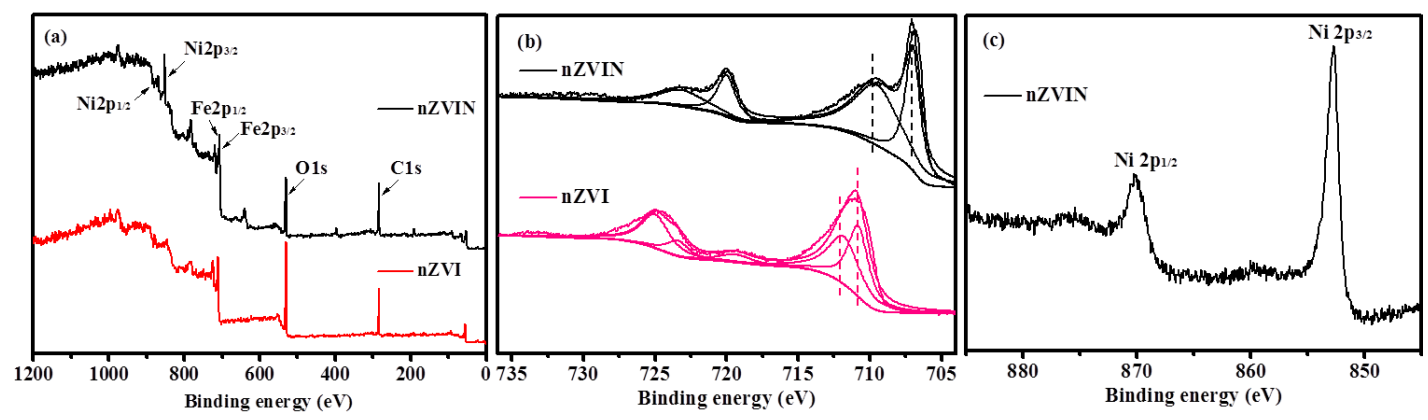

Figure 4. XPS wide-scan survey of the prepared nZVI and nZVIN (a); XPS Fe 2p survey of nZVI and nZVIN (b); and XPS Ni2p survey of nZVIN (c). 

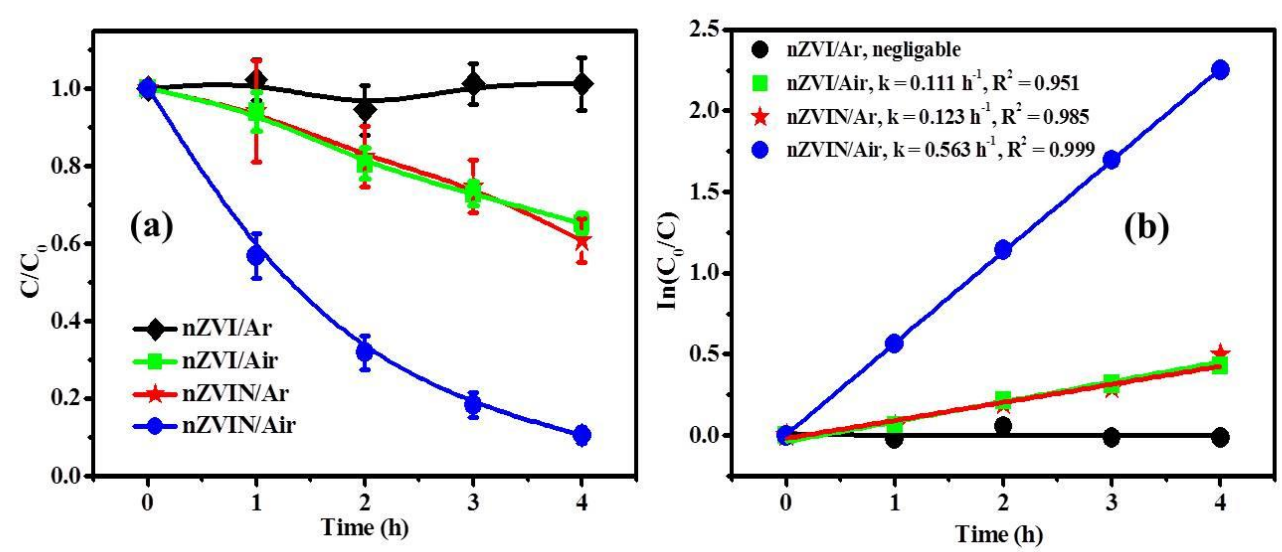

Figure 5. The temporal concentration change of $4-\mathrm{CP}$ as a function of reaction time during the aerobic degradation of $4-\mathrm{CP}$ in different systems (a); and plots of $\ln \left(\mathrm{C} / \mathrm{C}_{0}\right)$ versus time (b).

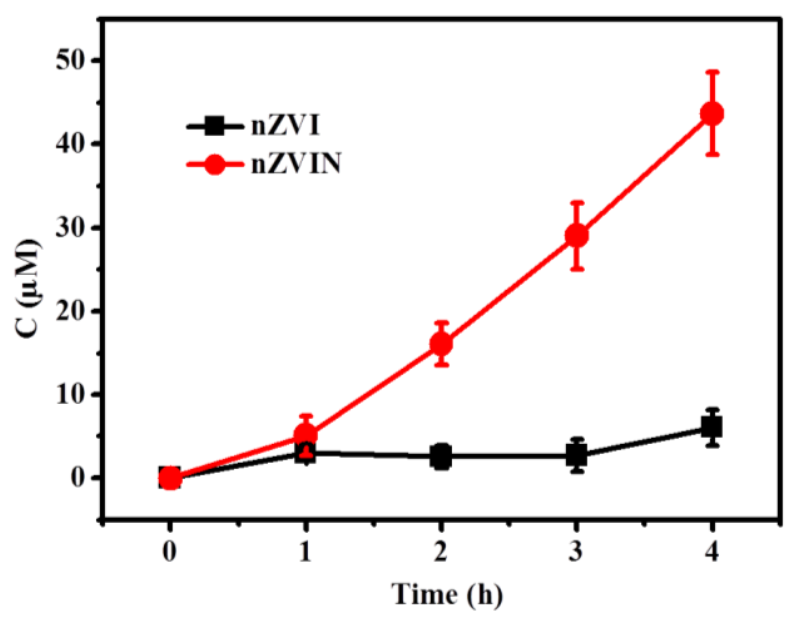

Figure 6. The temporal concentration change of hydrogen evolution over the as-prepared nZVI and nZVIN as a function of reaction time. 

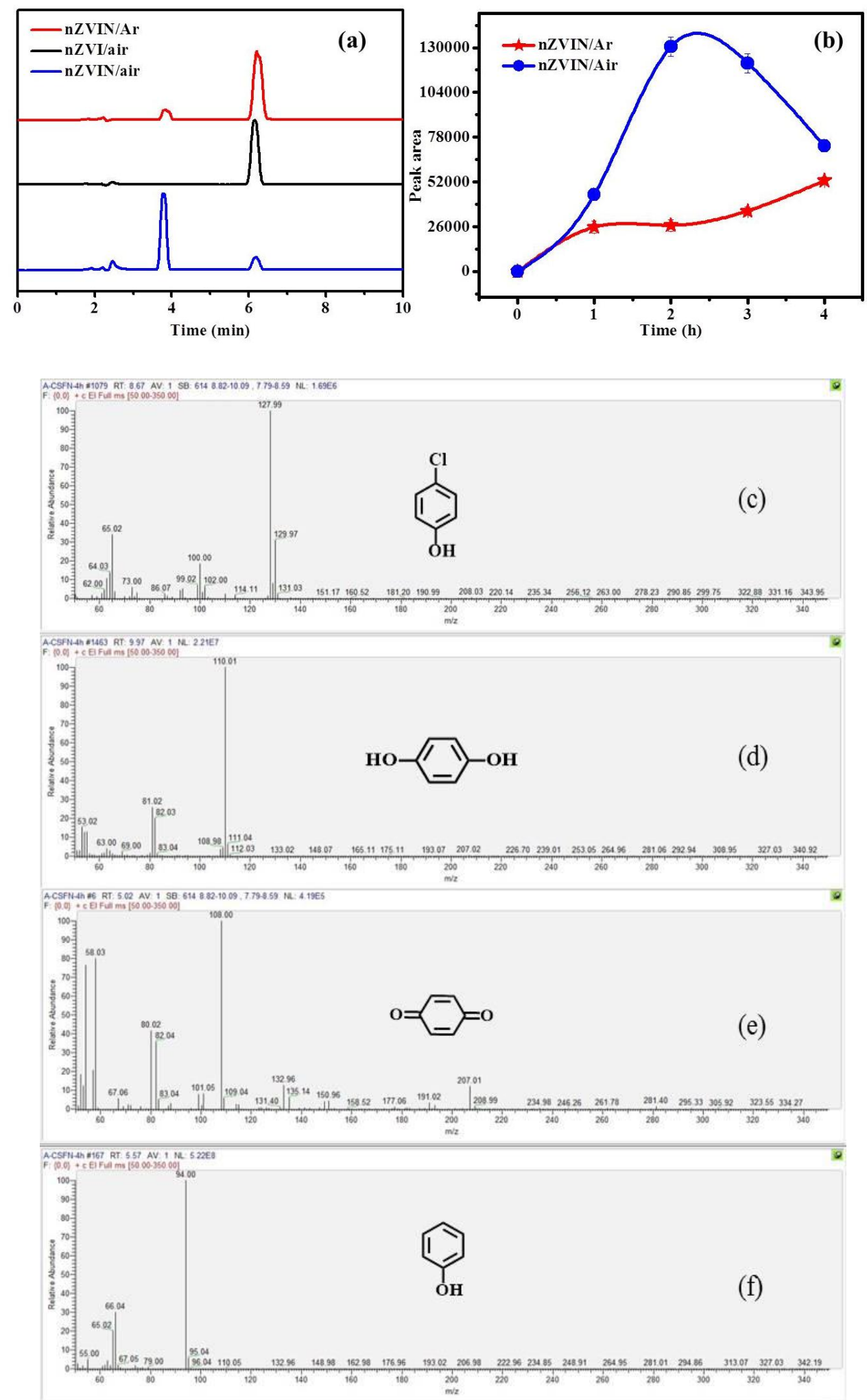

Figure 7. HPLC spectra (a); the amount of phenol generation during the nZVIN/Ar, and nZVIN/Air systems (b); GC-MS spectra of 4-CP (c), hydroquinone (d), 1,4-Benzoquinone (e), and phenol (f), reprentatively. 

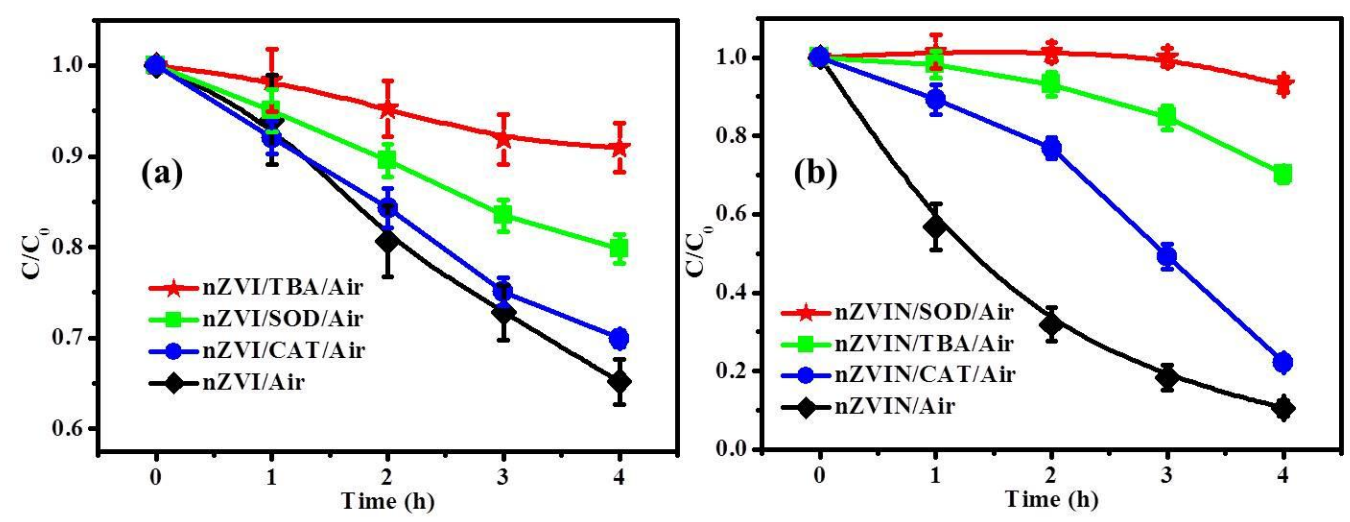

Figure 8. Time profiles of the 4-CP degradation in the nZVI/Air system (a), and the nZVIN/Air system (b) in the presence or absence of ROS scavengers.
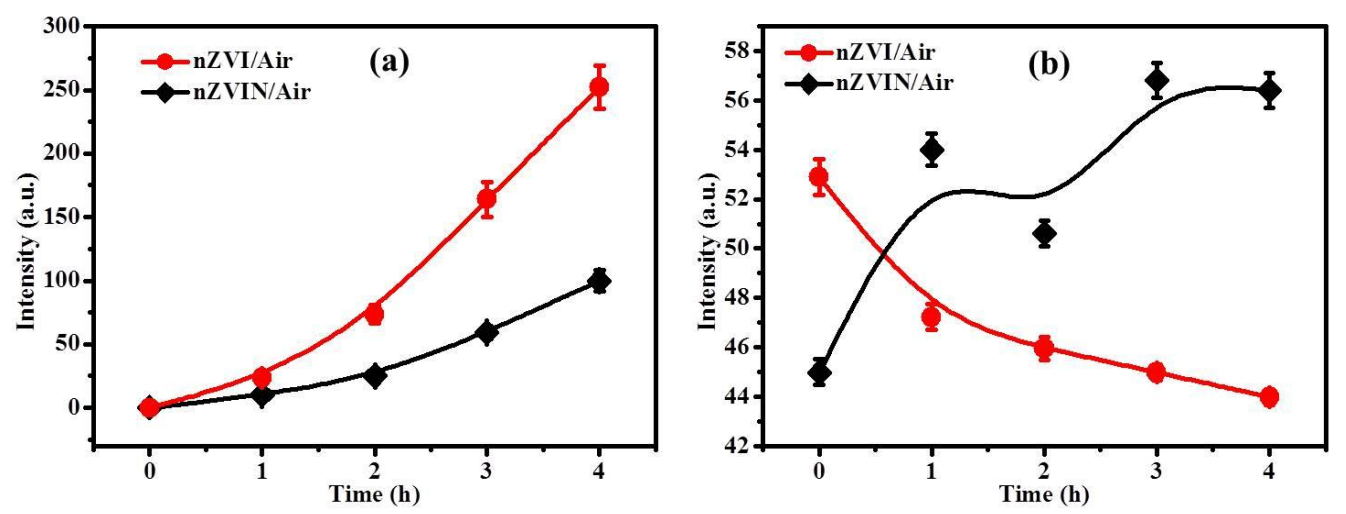

Figure 9. Measurement of $\cdot \mathrm{OH}$ (a), and $\mathrm{H}_{2} \mathrm{O}_{2}$ (b) in the nZVI/Air and nZVIN/Air systems. 


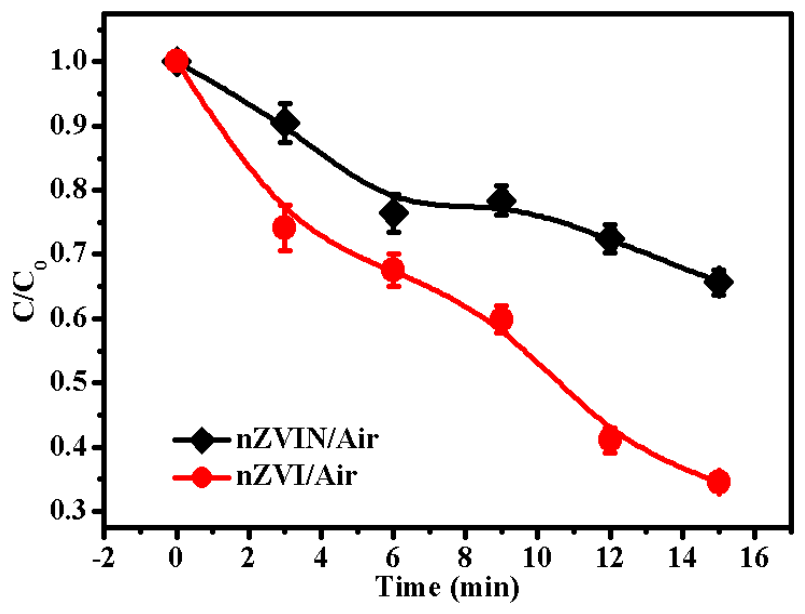

Figure 10. The decomposition of $\mathrm{H}_{2} \mathrm{O}_{2}$ in the nZVI/Air and nZVIN/Air systems.
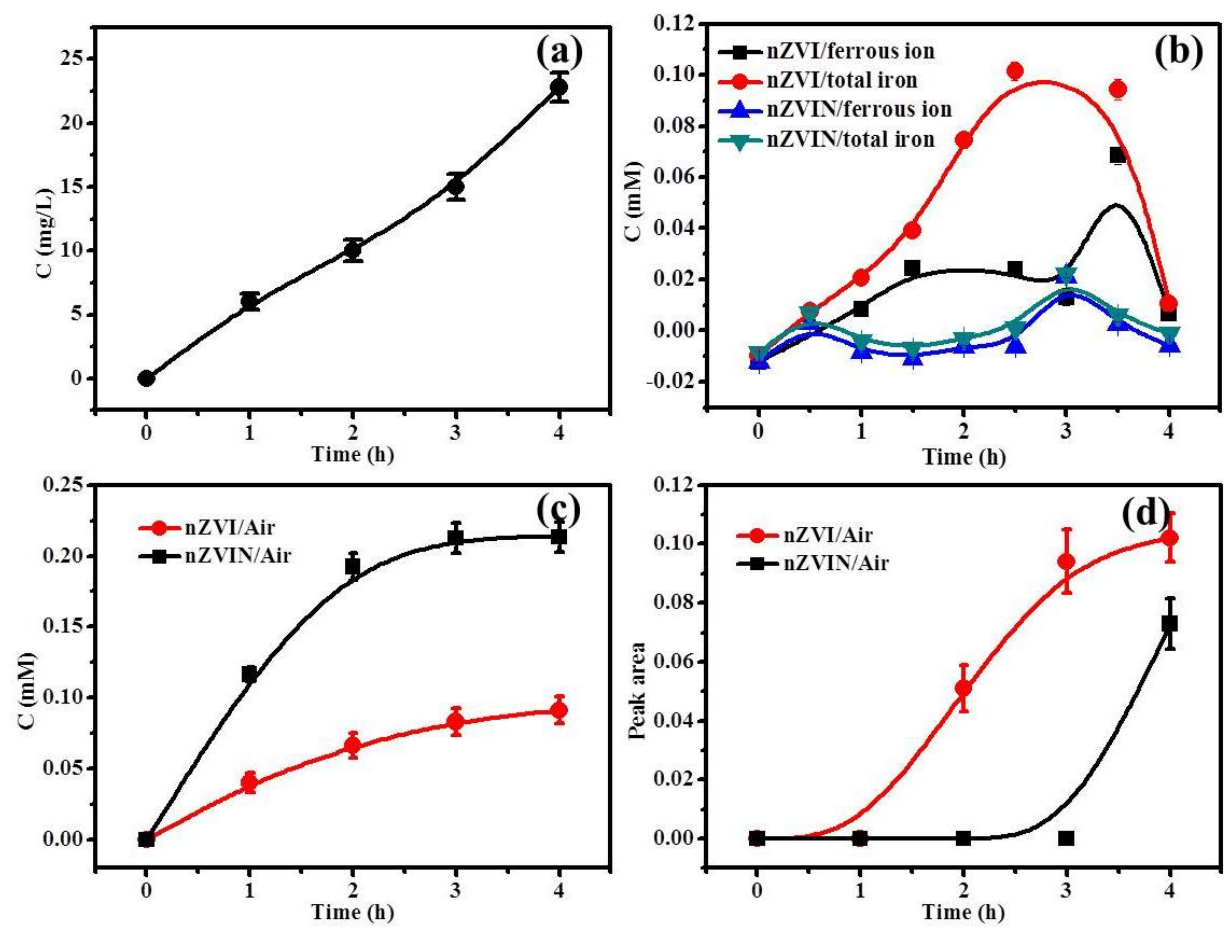

Figure 11. Variation of nickel ions (a); ferrous ions and total iron (b); chloride ions (c); andformic acid (d) concentrations in different systems during the 4-CP degradation. 


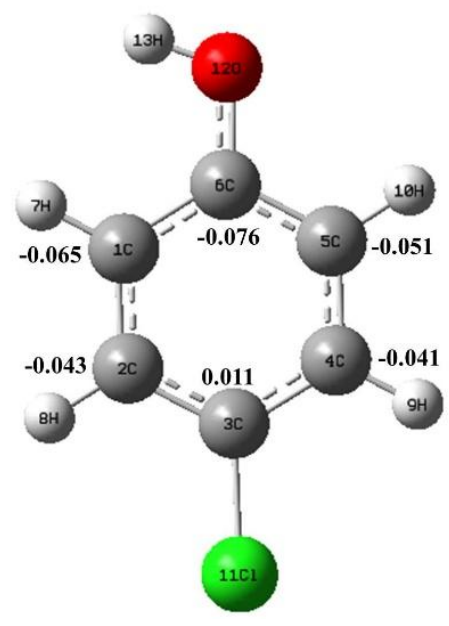

Figure 12. Hirshfeld charges for six carbons of a 4-CP molecule.

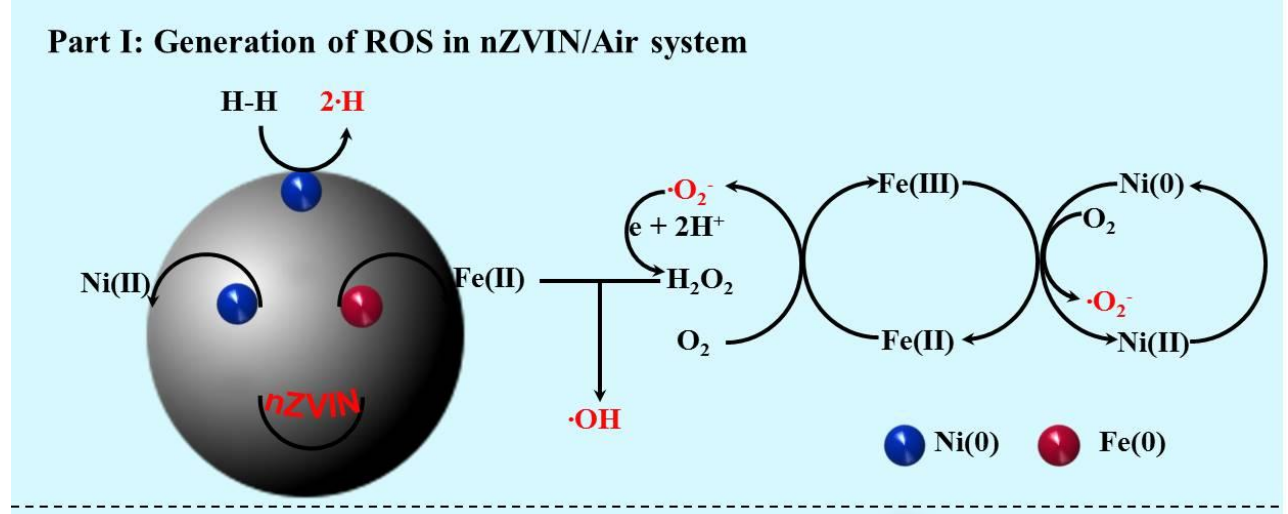

Part II: Degradation of 4-CP in nZVIN/Air system

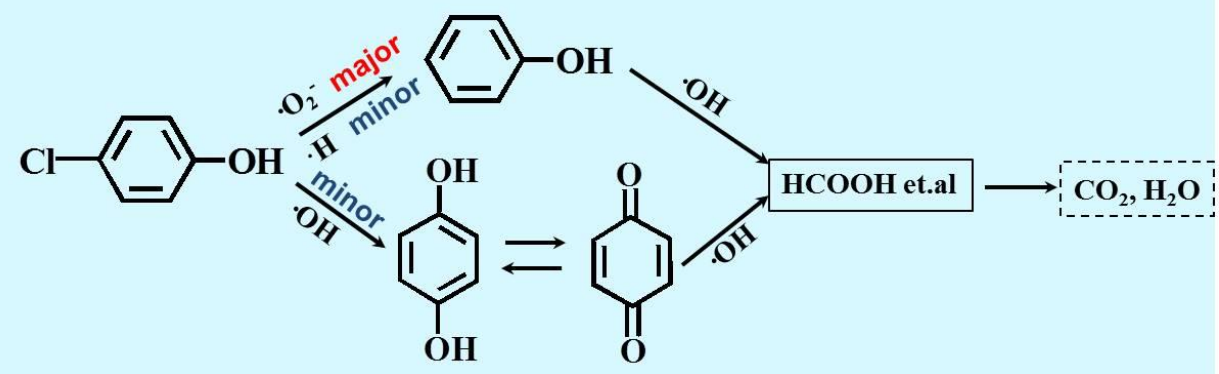

Scheme 1. The possible 4-CP degradation mechanism in the nZVIN/Air system. 


\section{Graphical Abstract}

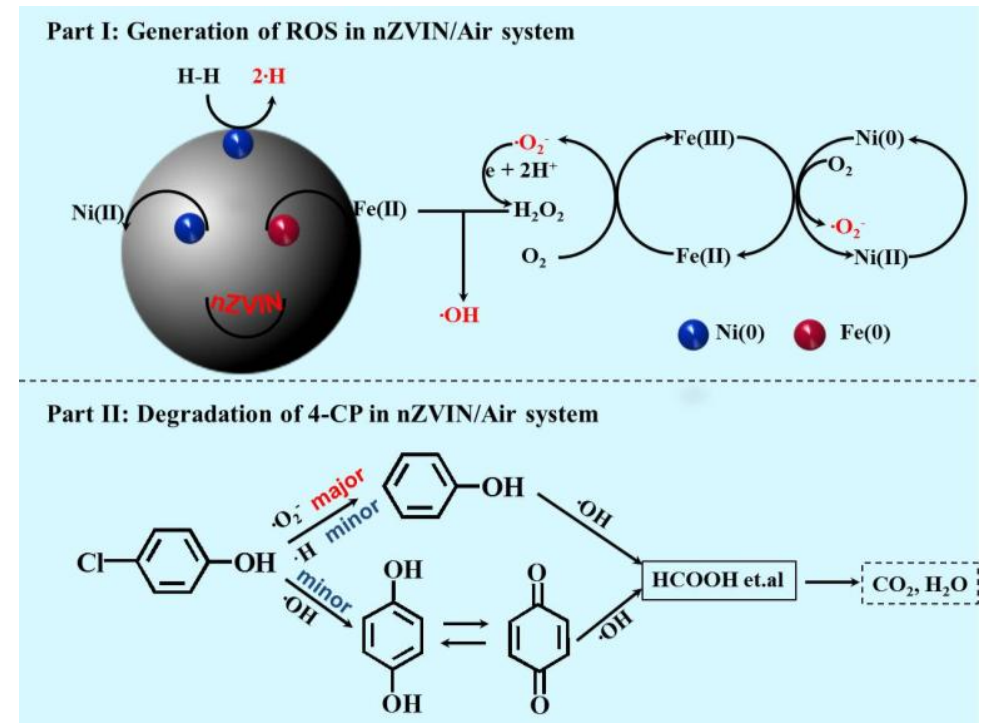

